\title{
Schwartzia succinivorans gen. nov., sp. nov., Another Ruminal Bacterium Utilizing Succinate as the Sole Energy Source
}

\author{
N. O. VAN GYLSWYK, ${ }^{1} \dagger$ H. HIPPE, ${ }^{2 *}$ AND F. A. RAINEY ${ }^{2}$ \\ Department of Animal Nutrition and Management, Swedish University of Agricultural Sciences, \\ Kungsängen Research Centre, S-753 23 Uppsala, Sweden, ${ }^{1}$ and DSMZ-Deutsche Sammlung \\ von Mikroorganismen und Zellkulturen GmbH, D-38124 Braunschweig, Germany ${ }^{2}$
}

\begin{abstract}
Four strains of gram-negative, anaerobic, non-spore-forming bacteria that were curved rods which were motile by means of flagella originating from the concave side of the cells and which fermented succinate quantitatively to propionate were isolated from high dilutions of rumen ingesta obtained from cows on pasture. The bacteria were asaccharolytic and not proteolytic and did not ferment amino acids or peptides. Succinate was the only substrate fermented. Rumen fluid together with yeast extract was required for good growth on succinate. Growth on succinate was enhanced in the presence of fumarate. The strains did not grow at $22^{\circ} \mathrm{C}$, and growth at $45^{\circ} \mathrm{C}$ was in all cases less than growth at $39^{\circ} \mathrm{C}$. The cellular fatty acid compositions of all four strains were determined. The DNA base composition was about $46 \mathrm{~mol} \% \mathrm{G}+\mathrm{C}$. The complete $16 \mathrm{~S}$ ribosomal DNA sequence of the type strain (strain S1-1) was determined, and the phylogenetic relationships were analyzed. The most closely related genera were the genera Selenomonas, Zymophilus, and Pectinatus, whereas the recently described succinate-fermenting organism Succiniclasticum ruminis was distantly related. The name proposed for these strains is Schwartzia succinivorans gen. nov., sp. nov.; the type strain is strain S1-1 (=DSM 10502). These organisms are common inhabitants of the rumina of cows on pasture.
\end{abstract}

In a previous paper (18) van Gylswyk described a ruminal bacterium, Succiniclasticum ruminis, which grew only on succinate (a variety of substrates were tested). It was isolated from the rumen of a cow fed a production ration containing grass silage as the main roughage source. The search for succinatefermenting rumen bacteria was continued, and a culture of gram-negative curved rods was obtained from a colony that developed on succinate agar medium inoculated with ingesta from the rumen of a cow on pasture. The culture fermented carbohydrate as well as succinate. Reisolation from this culture yielded only colonies of a bacterium that fermented carbohydrate but not succinate. This bacterium was characterized and named Pseudobutyrivibrio ruminis (19). It was suspected that the culture from which Pseudobutyrivibrio ruminis was isolated also contained a succinate-fermenting bacterium with morphology (gram-negative curved rods) similar to that of the non-succinate-fermenting bacterium. In this paper we describe four strains of a bacterium with such a morphology which is highly specific for succinate as a growth substrate. We propose that these strains should be named Schwartzia succinivorans gen. nov., sp. nov.

\section{MATERIALS AND METHODS}

Isolation. The composition of basal medium has been described previously (18). Medium containing rumen fluid $(40 \%)$ and agar $(2 \%)$ was preincubated at $39^{\circ} \mathrm{C}$ for 1 week (2), after which succinate $(0.5 \%), \mathrm{NaHCO}_{3}$, and a reducing agent solution (cysteine plus sodium sulfide) were added; the medium was then sterilized. Yeast extract was not included. Portions $(0.5 \mathrm{ml})$ of $10^{-7}$ dilutions of samples of homogenized rumen ingesta from each of six cows on pasture were injected into sterile, $\mathrm{CO}_{2}$-purged roll bottles (three roll bottles per sample). Then $2.5-\mathrm{ml}$ portions of molten $\left(47^{\circ} \mathrm{C}\right)$ preincubated succinate agar medium were injected into the roll bottles. The roll bottles were incubated for 5 days. Colonies were then counted, but very small colonies were ignored. After counting, colonies were picked for microscopic examination. In addition, a number of colonies were picked for culturing and stabbed into agar slopes containing succinate $(1 \%)$ and yeast extract $(0.5 \%)$. After growth for 1 day the slopes were stored at ca. $-80^{\circ} \mathrm{C}$. Bacteria were subsequently reisolated from colonies that de-

* Corresponding author.

† Retired 31 July 1996. veloped in roll bottles containing agar medium supplemented with $1 \%$ succinate and $0.25 \%$ yeast extract. The reisolated bacteria were examined for the ability to grow on succinate in basal medium containing $40 \%$ clarified rumen fluid and $0.5 \%$ yeast extract with or without $1 \%$ succinate by monitoring changes in optical density.

Characterization tests. The characterization tests and media used for these tests have been described previously (18). Modifications are described below; any other changes are mentioned where appropriate. Yeast extract was included in media at a concentration of $0.2 \%$. The ability to ferment carbohydrates (1\%) was assessed by measuring the change in $\mathrm{pH}$ of poorly buffered medium which was prepared with one-fifth the concentration of $\mathrm{NaHCO}_{3}$ in basal medium and whose $\mathrm{pH}$ was adjusted to $6.8 . \mathrm{O}_{2}$-free $\mathrm{N}_{2}$ was used instead of $\mathrm{CO}_{2}$. The period of incubation was at least 1 week. The ability to ferment the Na salts of acid substrates $(30 \mathrm{mM})$, as well as glycerol $(40 \mathrm{mM})$, was measured by determining the change in optical density at $600 \mathrm{~nm}$ over a period of at least $24 \mathrm{~h}$. All of the substrates except succinate, which was heat sterilized, were added to sterile media as concentrated, filter-sterilized solutions. The medium used for $\mathrm{H}_{2} \mathrm{~S}$ production contained $30 \mathrm{~g}$ of SIM medium (Difco) per liter. Proteolytic activity was assessed by determining the ability to liquefy gelatin. Flagella were observed microscopically after Leifson staining (5).

$\mathbf{G}+\mathbf{C}$ content of the DNA. Bacterial cells for determining the $\mathrm{G}+\mathrm{C}$ content of the DNA were grown in basal medium containing $80 \mathrm{mM}$ succinate. The cells were lysed with sodium dodecyl sulfate (8), the DNA was isolated and purified (9), and the $\mathrm{G}+\mathrm{C}$ content was estimated from the ratio of $A_{245}$ to $A_{270}$ (17). The calibration standards were DNAs from Escherichia coli $\mathrm{B}$, Micrococcus luteus, and calf thymus (all obtained from Sigma).

Cellular fatty acid analysis. Each of the strains was grown in $300 \mathrm{ml}$ of $40 \%$ rumen fluid medium containing $10 \mathrm{~g}$ of sodium succinate $\cdot 6 \mathrm{H}_{2} \mathrm{O}$ per liter and $2 \mathrm{~g}$ of yeast extract per liter. Each preparation was inoculated with $5 \mathrm{ml}$ of an actively growing culture and incubated for $24 \mathrm{~h}$ at $37^{\circ} \mathrm{C}$. The cells were harvested by centrifugation and washed twice with a $1 \% \mathrm{NaCl}$ solution. The cellular fatty acids were determined as described previously (19).

$16 \mathrm{~S}$ rDNA sequence determination. The $16 \mathrm{~S}$ ribosomal DNA (rDNA) was amplified from genomic DNA as described previously (12). Purified PCR products were sequenced by using a Taq DyeDeoxy terminator cycle sequencing kit (Applied Biosystems, Foster City, Calif.) according to the manufacturer's protocol. An Applied Biosystems model 373A DNA sequencer was used for electrophoresis of the sequence reaction mixtures.

16S rDNA sequence analysis. The 16S rDNA sequences determined in this study were manually aligned with the sequences of representative clostridia and related taxa. Evolutionary distances were calculated by using the method of Jukes and Cantor (7). The neighbor-joining method (13) was used to reconstruct a phylogenetic dendrogram from distance matrices.

Nucleotide sequence accession number. The nucleotide sequence of strain $\mathrm{S} 1-1^{\mathrm{T}}$ ( $\mathrm{T}=$ type strain $)$ has been deposited in the EMBL database under accession number Y09434. 


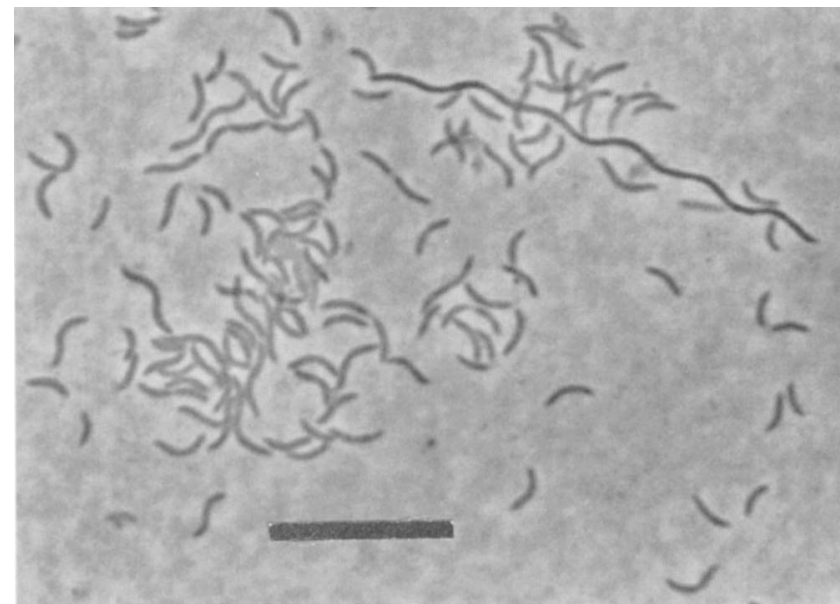

FIG. 1. Phase-contrast micrograph taken with an Axiophot microscope (Zeiss, Oberkochen, Germany) of cells of strain S1-1 ${ }^{\mathrm{T}}$ grown for $24 \mathrm{~h}$ on a rumen fluid-succinate agar slant. Bar $=10 \mu \mathrm{m}$.

\section{RESULTS AND DISCUSSION}

Isolation. Counts of colonies on preincubated succinate agar medium gave mean estimates of $2.5 \times 10^{8}, 2.2 \times 10^{8}$, and $2.2 \times$ $10^{8}$ bacteria per $g$ of rumen ingesta for two cows on pasture receiving no supplementary feed, two cows on pasture supplemented with a coarsely ground concentrate, and two cows on pasture supplemented with a finely ground concentrate mixture, respectively. Sixty colonies were picked nonselectively for microscopic examination; i.e., about 10 colonies for each cow were examined. A total of $43 \%$ of these contained gram-negative curved rods. Twenty of the larger colonies were picked for culturing and reisolation; 13 of these colonies comprised gram-negative curved rods, and one resembled Succiniclasticum ruminis (18). The latter colony together with 11 isolates of curved rods, fermented succinate. Four of the curved rod strains, strains $\mathrm{S} 1-1^{\mathrm{T}}, \mathrm{S} 2-3, \mathrm{~S} 3-2$, and $\mathrm{S} 4-2$, each of which was obtained from a different cow, were characterized and are described below.

Phenotypic characteristics. The cells of the strains are gramnegative, slightly curved to curved rods with tapered ends (Fig. 1). They are motile by means of flagella arising singly or in tufts from about the middle of the concave side of the cells. Spores are not produced. The cell width varies between 0.35 and 0.6 $\mu \mathrm{m}$, and the cell length varies between 1.6 and $3.3 \mu \mathrm{m}$. S shapes (probably two undivided cells) are up to about $5 \mu \mathrm{m}$ long, while long helical filaments (probably chains of undivided cells) can reach lengths of more than $30 \mu \mathrm{m}$.

After molten $40 \%$ rumen fluid- $0.2 \%$ yeast extract $-1 \%$ succinate-1.5\% agar medium which is cooled to produce slopes is inoculated and incubated for $24 \mathrm{~h}$, surface colonies are up to $0.25 \mathrm{~mm}$ in diameter. They are round with smooth edges, colorless, and slightly raised. Submerged colonies are round discs with diameters of about $0.1 \mathrm{~mm}$. After incubation for $48 \mathrm{~h}$, surface colonies have multiple lobes with smooth edges and are up to $5 \mathrm{~mm}$ in diameter. Submerged colonies are round discs with smooth edges and are up to $0.3 \mathrm{~mm}$ wide.

None of the four strains ferments galactose, glucose, fructose, mannose, arabinose, xylose, cellobiose, maltose, sucrose, glycerol, mannitol, the sodium salts of DL-lactic and pyruvic acids, the disodium salts of oxalic, malic, malonic, methylmalonic, fumaric, oxaloacetic, and glutaric acids, and the trisodium salts of citric, trans-aconitic, and tricarballylic acids. Amino acids and peptides in a medium containing $0.5 \%$ acid- hydrolyzed casein and $0.5 \%$ enzymically hydrolyzed casein do not support growth. Of the substrates tested, only succinate supports growth and is quantitatively converted to propionic acid. Carbon dioxide is probably produced, but this compound was not measured in our analysis. Both rumen fluid and yeast extract are required to obtain good growth on succinate. In medium containing $40 \mathrm{mM}$ succinate, $40 \%$ rumen fluid, and $0.2 \%$ yeast extract the shortest doubling time estimated from measurements of optical density at $600 \mathrm{~nm}$ in tubes having an inside diameter of $13.5 \mathrm{~mm}$ is almost $2 \mathrm{~h}$.

Although fumarate does not support growth, it supplies energy for growth when it is supplied together with succinate. The mean maximum optical densities for the four strains in medium containing $40 \%$ rumen fluid, $0.2 \%$ yeast extract, and $40 \mathrm{mM}$ succinate and in medium containing $40 \%$ rumen fluid, $0.2 \%$ yeast extract, $40 \mathrm{mM}$ succinate, and $10 \mathrm{mM}$ fumarate were 0.23 and 0.28 , respectively. Growth is not inhibited by fumarate when equimolar amounts of fumarate and succinate (40 $\mathrm{mM}$ each) are included; however, growth is slower and maximum optical densities are not as high as they are with 80 $\mathrm{mM}$ succinate, but they are higher than they are with $60 \mathrm{mM}$ succinate. Malonate does not inhibit growth on succinate at equimolar concentrations ( $30 \mathrm{mM}$ each).

None of the four strains liquefies gelatin, produces hydrogen sulfide, reduces nitrate, or synthesizes urease or catalase.

Growth in medium prepared under anoxic conditions is similar irrespective of whether a reducing agent (cysteine plus sulfide) is included, but when air $(2 \mathrm{ml}$ per $5 \mathrm{ml}$ of medium in $13-\mathrm{ml}$ tubes) is added to medium lacking a reducing agent, little growth occurs. There is no growth at $22^{\circ} \mathrm{C}$, but the strains respond differently to incubation at $45^{\circ} \mathrm{C}$. The approximate maximum optical densities when strains S4-2, S1-1 ${ }^{\mathrm{T}}, \mathrm{S} 2-3$, and S3-2 are incubated at $45^{\circ} \mathrm{C}$ are $0.01,0.03,0.08$, and 0.14 , respectively, compared with optical densities of 0.18 to 0.20 after incubation at $39^{\circ} \mathrm{C}$ in medium containing $1 \%(37 \mathrm{mM})$ succinate

DNA base composition. The mean $\mathrm{G}+\mathrm{C}$ content of the DNA is about $46 \mathrm{~mol} \%$ (46.2 and $46.6 \mathrm{~mol} \%$ for strain S1- ${ }^{\mathrm{T}}$ and 45.3 and $47.3 \mathrm{~mol} \%$ for strain S3-2 in separate determinations).

Cellular fatty acids. The major cellular fatty acid components are saturated straight-chain $\mathrm{C}_{12: 0}, \mathrm{C}_{14: 0}, \mathrm{C}_{15: 0}$, and $\mathrm{C}_{16: 0}$ acids, and a straight-chain $\mathrm{C}_{16: 1}$ cis 7 acid and a $\mathrm{C}_{15: 0}$ aldehyde are also present when the organisms are grown in medium containing rumen fluid; iso, anteiso, cyclopropane, and hydroxy fatty acids were not detected (Table 1).

Phylogenetic analysis. An almost complete 16S rDNA sequence ( $>95 \%$ of the $E$. coli $16 \mathrm{~S}$ rDNA sequence) was determined for strain S1-1 ${ }^{\mathrm{T}}$. Partial $16 \mathrm{~S}$ rDNA sequences comprising the 500 bases of the $5^{\prime}$ end of the 16S rDNA were determined for the other three strains described in this study. The partial sequences were found to be identical to the strain $\mathrm{S} 1-1^{\mathrm{T}}$ sequence in the region compared, and therefore, these organisms are considered highly related.

When the $16 \mathrm{~S}$ rDNA sequence of strain $\mathrm{S} 1-1^{\mathrm{T}}$ was compared with all of the $16 \mathrm{~S}$ rDNA sequences of clostridia and related taxa available, it was most similar to the sequences of Selenomonas species. Strain $S 1-1^{\mathrm{T}}$ falls in the radiation that includes the genera Selenomonas and Zymophilus (Fig. 2), a phylogenetic cluster designated cluster IX by Collins et al. (1). The new bacterium is phylogenetically unrelated to Pseudobutyrivibrio ruminis, which falls in cluster XIVa (19). The $16 \mathrm{~S}$ rDNA sequence similarities between strain $\mathrm{S} 1-1^{\mathrm{T}}$ and the Selenomonas and Zymophilus species shown in Fig. 2 range from 87.9 to $89.8 \%$. Strain $\mathrm{S} 1-1^{\mathrm{T}}$ is clearly as phylogenetically distinct from the Selenomonas species as Zymophilus paucivorans is. Boot- 
TABLE 1. Cellular fatty acid composition of Schwartzia succinivorans and comparison with the mean values for the neighboring genera Selenomonas and Pectinatus

\begin{tabular}{|c|c|c|c|c|c|c|c|c|}
\hline \multirow{3}{*}{$\begin{array}{c}\text { Equivalent } \\
\text { chain } \\
\text { length }\end{array}$} & \multirow{3}{*}{$\begin{array}{c}\text { Fatty acid } \\
\text { methyl } \\
\text { ester }^{a}\end{array}$} & \multicolumn{7}{|c|}{$\%$ in: } \\
\hline & & \multicolumn{4}{|c|}{ Schwartzia succinivorans strains $^{b}$} & \multicolumn{2}{|c|}{$\begin{array}{l}\text { Selenomonas } \\
\left(^{(7 \text { species })^{c}}\right.\end{array}$} & \multirow{2}{*}{ Pectinatus $^{c}$} \\
\hline & & $\mathrm{S} 1-1^{\mathrm{T}}$ & S2-3 & S3-2 & S4-2 & Mean & Range & \\
\hline 10.910 & Unknown & 1.6 & 1.9 & 1.9 & 1.6 & & & \\
\hline 11.000 & $11: 0$ & 1.2 & 1.1 & 1.0 & 1.1 & 5 & $4-7$ & 11 \\
\hline 12.000 & $12: 0$ & 12.4 & 11.8 & 11.5 & 12.0 & 3 & $2-4$ & $0^{d}$ \\
\hline 13.000 & $13: 0$ & 1.6 & 1.5 & 1.3 & 1.4 & 11 & $3-17$ & 4 \\
\hline 13.952 & Unknown & 1.3 & 1.2 & 1.1 & 1.1 & & & \\
\hline 14.000 & $14: 0$ & 8.3 & 8.3 & 9.7 & 8.2 & 2 & $1-4$ & 1 \\
\hline 14.465 & $14: 0 \mathrm{dma}$ & 1.1 & 0.9 & 0.9 & 0.9 & 17 & $10-22$ & 18 \\
\hline 14.499 & Unknown & 1.3 & 1.4 & 1.3 & 1.3 & & & \\
\hline 14.753 & Unknown & 1.1 & 1.1 & 0.9 & 1.0 & & & \\
\hline 14.790 & $15: 1 c 7$ & 0.8 & 1.0 & 0.0 & 1.0 & & & \\
\hline 15.000 & $15: 0$ & 10.4 & 8.3 & 9.6 & 8.3 & 13 & $9-17$ & 21 \\
\hline 15.479 & 15:0 dma & 20.4 & 20.6 & 20.1 & 20.5 & 5 & $3-10$ & 1 \\
\hline 15.769 & $16: 1 c 7$ & 13.1 & 15.6 & 12.2 & 15.6 & 6 & $3-16$ & 3 \\
\hline 16.000 & $16: 0$ & 9.5 & 8.4 & 12.0 & 8.4 & 1 & $0-4$ & 2 \\
\hline 16.240 & $16: 1 c 7 \mathrm{dma}$ & 4.5 & 5.4 & 3.9 & 5.4 & & & \\
\hline 16.479 & $16: 0 \mathrm{dma}$ & 3.6 & 3.3 & 3.7 & 3.4 & & & \\
\hline 17.000 & $17: 0$ & 1.2 & 1.0 & 1.3 & 1.0 & & & \\
\hline 17.763 & $18: 1 c 9$ & 2.2 & 2.6 & 2.6 & 2.8 & 3 & $1-6$ & 2 \\
\hline 18.000 & $18: 0$ & 5.4 & 5.4 & 6.0 & 5.3 & $0^{d}$ & & 1 \\
\hline 18.222 & $18: 1 c 9 \mathrm{dma}$ & 1.1 & 1.1 & 0.7 & 1.0 & & & \\
\hline
\end{tabular}

${ }^{a}$ Abbreviations: dma, dimethylacetal (equivalent to aldehyde); $c$, cis.

${ }^{b}$ Fatty acids present in the four strains at levels less than $1 \%$ are not listed.

${ }^{c}$ Data from reference 10.

${ }^{d}$ Less than $0.5 \%$ of the total fatty acids.

strap analyses indicate that the branch points of the Selenomonas, Zymophilus, Pectinatus, and Schwartzia lineages are unstable, with values ranging from 50 to $74 \%$. The exact branch point of the genus Schwartzia cannot therefore be determined with confidence, a fact that supports its designation as a new taxon.

Differentiation from other taxa. As noted above, the phylogenetic analysis showed that the new bacterium is most closely related to the genera Selenomonas and Zymophilus. Phenotypic similarities are also apparent (Table 2). However, there are important differences in other characteristics. The new strains do not ferment carbohydrates or any of the other substrates tested except succinate, while most species of the genera Selenomonas, Zymophilus, and Pectinatus (which is more distantly related) do ferment carbohydrates; the only exception is Selenomonas acidaminophila, which ferments lactate, pyruvate, and glutamate (4). Second, members of the genera Pectinatus and Selenomonas, including Selenomonas sputigena, Selenomonas artemidis, Selenomonas dianae, Selenomonas flueggeii, Selenomonas infelix, Selenomonas noxia, Selenomonas ruminantium subsp. ruminantium, and Selenomonas ruminantium subsp. lactilytica (10), differ markedly from our strains in cellular fatty acid composition, notably in the levels of $\mathrm{C}_{12: 0}$ and $\mathrm{C}_{16: 0}$ fatty acids and $\mathrm{C}_{14: 0}$ and $\mathrm{C}_{15: 0}$ dimethylacetals (aldehydes) (Table 1). The cellular fatty acid content of the Zymophilus species is not yet known. Third, the $\mathrm{G}+\mathrm{C}$ contents of the DNAs of the new strains (about 46 mol\%) differ from the $\mathrm{G}+\mathrm{C}$ contents of Zymophilus and Pectinatus species (38 to 41 $\mathrm{mol} \%$ ) and Selenomonas species (48 mol\% and higher) (Table 2 ). Although the new bacterium is not phylogenetically closely related to the genus Succiniclasticum, the new bacterium and Succiniclasticum ruminis have a number of phenotypic characteristics in common, especially the use of succinate as the only substrate which is fermented to propionate. However, the new

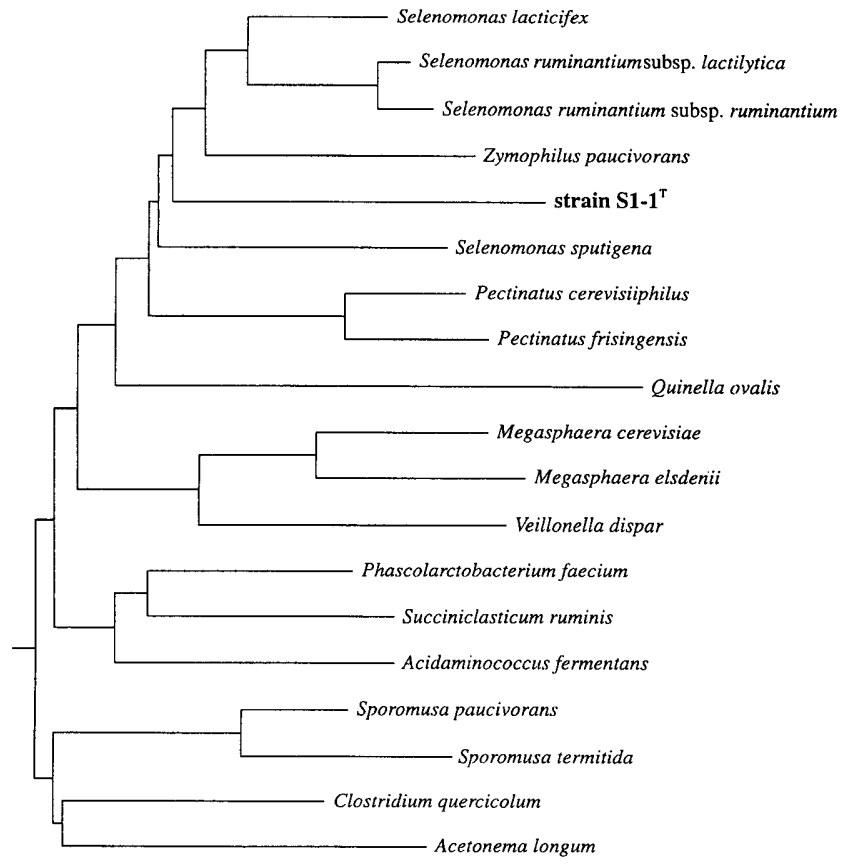

$5 \%$

FIG. 2. Phylogenetic dendrogram based on a $16 \mathrm{~S}$ rDNA-rRNA sequence comparison, showing the position of strain $\mathrm{S} 1-1^{\mathrm{T}}$ among representatives of cluster IX as defined by Collins et al. (1). 
TABLE 2. Characteristics that distinguish Schwartzia succinivorans from taxa that exhibit genotypic relatedness ${ }^{a}$

\begin{tabular}{|c|c|c|c|c|c|c|}
\hline Species & Cell shape & Flagella & $\begin{array}{l}\text { Saccharo- } \\
\text { lytic }\end{array}$ & $\begin{array}{l}\text { Major } \\
\text { fermenta- } \\
\text { tion ac- } \\
\text { id(s) }{ }^{b}\end{array}$ & $\begin{array}{l}\mathrm{G}+\mathrm{C} \text { con- } \\
\text { tent of DNA } \\
(\text { mol\% })^{c}\end{array}$ & $\begin{array}{l}\text { Refer- } \\
\text { ence(s) }\end{array}$ \\
\hline Schwartzia succinivorans & $\begin{array}{l}\text { Curved rods, crescents, S-shapes, } \\
\text { helical chains }\end{array}$ & $\begin{array}{l}\text { One or more located at about the } \\
\text { middle of the concave side of cell }\end{array}$ & - & $P$ & 46 & \\
\hline Zymophilus paucivorans & Curved or helical rods & Not stated (motile) & + & $\mathrm{A}, \mathrm{P}$ & $39-41$ & 14 \\
\hline Zymophilus raffinosivorans & Straight to slightly curved rods & Not stated (motile) & + & $\mathrm{A}, \mathrm{P}$ & $38-41$ & 14 \\
\hline Pectinatus cerevisiiphilus & $\begin{array}{l}\text { Slightly curved rods and helical } \\
\text { filaments }\end{array}$ & Comb-like from one side of cell & + & $\mathrm{A}, \mathrm{P}$ & $38-41$ & 14 \\
\hline Pectinatus frisingensis & $\begin{array}{l}\text { Slightly curved rods and helical } \\
\text { filaments }\end{array}$ & Not stated (usually motile) & + & $\mathrm{A}, \mathrm{P}$ & $38-41$ & 14 \\
\hline Selenomonas lacticifex & Curved, crescent-shaped rods & Not stated (motile) & + & $\mathrm{A}, \mathrm{P}, \mathrm{L}$ & $51-52$ & 14 \\
\hline Selenomonas sputigena & Curved, crescent-shaped rods & One or more subpolar & + & $\mathrm{A}, \mathrm{P}$ & 57 & 5,14 \\
\hline Selenomonas ruminantium & Curved, crescent-shaped rods & $\begin{array}{l}\text { Groups located at the middle of } \\
\text { the concave side of cells }\end{array}$ & + & $\mathrm{A}, \mathrm{P}, \mathrm{L}^{d}$ & $48-53$ & 14,15 \\
\hline
\end{tabular}

\footnotetext{
${ }^{a}$ All taxa are non-spore-forming, mesophilic, strictly anaerobic, gram-negative bacteria.

${ }^{b} \mathrm{~A}$, acetate; $\mathrm{P}$, propionate; L, lactate.

${ }^{c}$ The $\mathrm{G}+\mathrm{C}$ contents of the DNAs of 11 Selenomonas species range from 48 to $58 \mathrm{~mol} \%$ (4).

a Selenomonas ruminantium subsp. lactilytica can produce or ferment lactate.
}

bacterium differs from Succiniclasticum ruminis in the shape and size of its cells, by its motility by means of lateral flagella, and in DNA G $+\mathrm{C}$ content (difference, $7 \mathrm{~mol} \%$ ).

These results, together with the low levels of phylogenetic relatedness to the most closely related genera, led us to the conclusion that our new strains represent a new genus.

Description of Schwartzia gen. nov. Schwartzia (Schwart'zi.a. L. fem. n. Schwartzia, named in memory of Helen M. Schwartz, a South African rumen physiologist who had a keen interest in rumen microbiology). The genus comprises bacteria that are gram-negative, anaerobic, non-spore-forming, curved rods that are motile by means of lateral flagella. They are asaccharolytic and do not ferment amino acids or peptides but do ferment succinic acid with the production of propionic acid. They are not proteolytic and do not produce catalase or urease or reduce nitrate. Mesophilic. The $\mathrm{G}+\mathrm{C}$ content of the DNA is about $46 \mathrm{~mol} \%$. The only species is the type species, Schwartzia succinivorans.

Description of Schwartzia succinivorans sp. nov. Schwartzia succinivorans (suc.cin.i.vo' rans. L. adj. succinicus, succinic acid; L. part. vorans, devouring; L. fem. adj. succinivorans, succinic acid devouring). Each cell is a curved rod with one or more flagella emanating from the concave side at approximately the middle of the cell; the flagella occur in tufts if more than one flagellum is present. Cells are 0.35 to 0.6 by 1.6 to $3.3 \mu \mathrm{m}$. S-shaped cells and helical filaments up to $30 \mu \mathrm{m}$ long can be formed. Colonies on succinate agar are colorless and slightly raised with multiple lobes and smooth edges and are up to $5 \mathrm{~mm}$ in diameter after $48 \mathrm{~h}$. The optimum temperature for growth is $39^{\circ} \mathrm{C}$, and no growth occurs at $22^{\circ} \mathrm{C}$ and around $45^{\circ} \mathrm{C}$. Succinate is fermented with propionate as the only fermentation end product. Rumen fluid and yeast extract are required for good growth. The following carbon sources are not utilized: carbohydrates, glycerol, lactate, pyruvate, oxalate, malate, malonate, methylmalonate, fumarate, oxalacetate, glutarate, citrate, aconitate, tricarballylate, and amino acids and peptides present in acid or enzymic hydrolysates of casein. Tests for catalase, urease, sulfide production, nitrate reduction, and gelatin liquefaction are negative.

The cellular fatty acid composition (means of values obtained for four strains) is as follows: $20 \% \mathrm{C}_{15: 0}$ aldehyde, $14 \%$ $\mathrm{C}_{16: 1} \operatorname{cis} 7,12 \% \quad \mathrm{C}_{12: 0}, 9 \% \quad \mathrm{C}_{14: 0}, 9 \% \mathrm{C}_{15: 0}$, and $9 \% \mathrm{C}_{16: 0}$.
Branched-chain fatty acids are absent. The $\mathrm{G}+\mathrm{C}$ content of the DNA is $46 \mathrm{~mol} \%$ (as determined by UV spectroscopy).

Strain S1-1 is the type strain. The four strains examined have been deposited in the Deutsche Sammlung von Mikroorganismen und Zellkulturen under the following accession numbers: strain S1-1 ${ }^{\mathrm{T}}$, DSM $10502^{\mathrm{T}}$; strain S2-3, DSM 10503, strain S3-2, DSM 10504; and strain S4-2, DSM 10505.

Ecological significance. The discovery of a second rumen bacterium highly specific for succinate suggests that succinate breakdown to propionate in the rumen occurs largely in bacteria of this type. These organisms rank with other highly specific bacteria, such as the methanogens, that found particular niches in a very competitive environment. The reason for such an evolutionary direction may lie in the fact that very little energy is derived from succinate decarboxylation (16). In organisms that are capable of utilizing substrates with higher molar ATP yields the ability to ferment succinate would be of little importance in their energy supply in an environment where carbohydrates dominate and where other breakdown products of ruminant diets, such as lactate and amino acids, provide more energy. Thus, the specific succinate-fermenting organisms are favored because they have an inferior but constant energy source which can be utilized even in the presence of more energy-rich substrates.

Succinate is an important fermentation product of Prevotella ruminicola, which often occurs in its highest numbers among bacteria in the rumen, and is also produced by other species, including the actively cellulose-degrading bacteria Fibrobacter succinogenes and Ruminococcus flavefaciens. Lactate is at least partially converted to propionate in the rumen, but Hungate (6) summarized results of work which showed that the turnover of succinate far exceeds the turnover of lactate. Thus, specific succinate fermenters could be responsible for the bulk of the propionate produced in the rumen. In the case of ruminants fed a good-quality silage with a high lactate content, the lactate-fermenting bacteria could contribute meaningfully to ruminal propionate production.

Previous work (18) gave no indication of the presence of Schwartzia succinivorans-like bacteria in the rumina of cows feeding on grass silage. Only Succiniclasticum ruminis was found. However, a strain of the latter species was isolated from the rumen of a cow on pasture. The present study shows that 
although Succiniclasticum ruminis-like bacteria occur in the rumina of cows on pasture, the majority of specific succinatefermenting bacteria resemble Schwartzia succinivorans. Thus, it appears that the roughage component of the diet influences the occurrence of these two species. There may be other species associated with other diets. The rumen is not the only intestinal habitat colonized by bacteria of this type. The hindgut of the koala (Phascolarctos sp.) is also inhabited by such a bacterium (viz. Phascolarctobacterium faecium) $(3,11)$. It is possible that even more succinate-specific intestinal bacteria will be found.

\section{ACKNOWLEDGMENTS}

We thank Reiner Kroppenstedt and Birgit Frerichs for their help with the cellular fatty acid analysis and Barbro Näslund for the volatile fatty acid analysis.

\section{REFERENCES}

1. Collins, M. D., P. A. Lawson, A. Willems, J. J. Cordoba, J. FernandezGarayzabal, P. Garcia, J. Cai, H. Hippe, and J. A. E. Farrow. 1994. The phylogeny of the genus Clostridium: proposal of five new genera and eleven new species combinations. Int. J. Syst. Bacteriol. 44:812-826.

2. Dehority, B. A., and J. A. Grubb. 1976. Basal medium for the selective enumeration of rumen bacteria utilizing specific energy sources. Appl. Environ. Microbiol. 32:703-710.

3. Del Dot, T., R. Osawa, and E. Stackebrandt. 1993. Phascolarctobacterium faecium gen. nov., spec. nov., a novel taxon of the Sporomusa group of bacteria. Syst. Appl. Microbiol. 16:380-384.

4. Hespell, R. B., B. J. Paster, and F. E. Dewhirst. 1992. The genus Selenomo nas, p. 2005-2013. In A. Balows, H. G. Trüper, M. Dworkin, W. Harder, and K.-H. Schleifer (ed.), The prokaryotes, 2nd ed., vol. 2. Springer-Verlag, New York, N. Y

5. Holdeman, L. V., E. P. Cato, and W. E. C. Moore (ed.). 1977. Anaerobe laboratory manual, 4th ed. Virginia Polytechnic Institute and State University, Blacksburg.

6. Hungate, R. E. 1966. The rumen and its microbes. Academic Press, Inc., New York, N. Y
7. Jukes, T. H., and C. R. Cantor. 1969. Evolution of protein molecules, p. 21-132. In H. N. Munro (ed.), Mammalian protein metabolism. Academic Press, New York, N. Y.

8. Marmur, J. 1961. A procedure for the isolation of deoxyribonucleic acid from micro-organisms. J. Mol. Biol. 3:208-218.

9. Meyer, S. A., and K. H. Schleifer. 1975. Rapid procedure for the approximate determination of the deoxyribonucleic acid base composition of micrococci, staphylococci, and other bacteria. Int. J. Syst. Bacteriol. 25:383385.

10. Moore, L. V. H., D. M. Bourne, and W. E. C. Moore. 1994. Comparative distribution and taxonomic value of cellular fatty acids in thirty-three genera of anaerobic gram-negative bacilli. Int. J. Syst. Bacteriol. 44:338-347.

11. Osawa, R., T. Fujisawa, and T. Mitsuoka. 1992. Characterization of gramnegative anaerobic strains, isolated from koala faeces, which exhibit satellite growth and pleomorphism. Syst. Appl. Microbiol. 15:628-635.

12. Rainey, F. A., N. Ward-Rainey, R. M. Kroppenstedt, and E. Stackebrandt 1996. The genus Nocardiopsis represents a phylogenetically coherent taxon and a distinct actinomycete lineage: proposal of Nocardiopsaceae fam. nov. Int. J. Syst. Bacteriol. 46:1088-1092.

13. Saitou, N., and M. Nei. 1987. The neighbor-joining method: a new method for reconstructing phylogenetic trees. Mol. Biol. Evol. 4:406-425.

14. Schleifer, K. H., M. Leuteritz, N. Weiss, W. Ludwig, G. Kirchhof, and H. Seidel-Rüfer. 1990. Taxonomic study of anaerobic, gram-negative, rodshaped bacteria from breweries: emended description of Pectinatus cerevisiiphilus and description of Pectinatus frisingensis sp. nov., Selenomonas lacticifex sp. nov., Zymophilus raffinosivorans gen. nov. sp. nov., and Zymophilus paucivorans, sp. nov. Int. J. Syst. Bacteriol. 40:19-27.

15. Stewart, C. S., and M. P. Bryant. 1988. The rumen bacteria, p. 21-75. In P. N Hobson (ed.), The rumen microbial ecosystem. Elsevier Applied Science, London, United Kingdom.

16. Thauer, R. K., K. Jungermann, and K. Decker. 1977. Energy conservation in chemotrophic anaerobic bacteria. Bacteriol. Rev. 41:100-180.

17. Ulitzur, S. 1972. Rapid determination of DNA base composition by ultraviolet spectroscopy. Biochim. Biophys. Acta 272:1-11.

18. van Gylswyk, N. O. 1995. Succiniclasticum ruminis gen. nov., sp. nov., a ruminal bacterium converting succinate to propionate as the sole energyyielding mechanism. Int. J. Syst. Bacteriol. 45:297-300.

19. van Gylswyk, N. O., H. Hippe, and F. A. Rainey. 1996. Pseudobutyrivibrio ruminis gen. nov., sp. nov., a butyrate-producing bacterium from the rumen that closely resembles Butyrivibrio fibrisolvens in phenotype. Int. J. Syst. Bacteriol. 46:559-563. 